\title{
Effect of Timing of Water Deficit on Pearl Millet (Pennisetum americanum $)^{1}$
}

V. MAHALAKSHMI, F.R. BIDINGER and D.S. RAJU

International Crops Research Institute for the Semi-Arid Tropics (ICRISAT), Patancheru P.O., Andhra Pradesh 502324 (India)

${ }^{1}$ ICRISAT Journal article No 547.

(Accepted 24 July 1986)
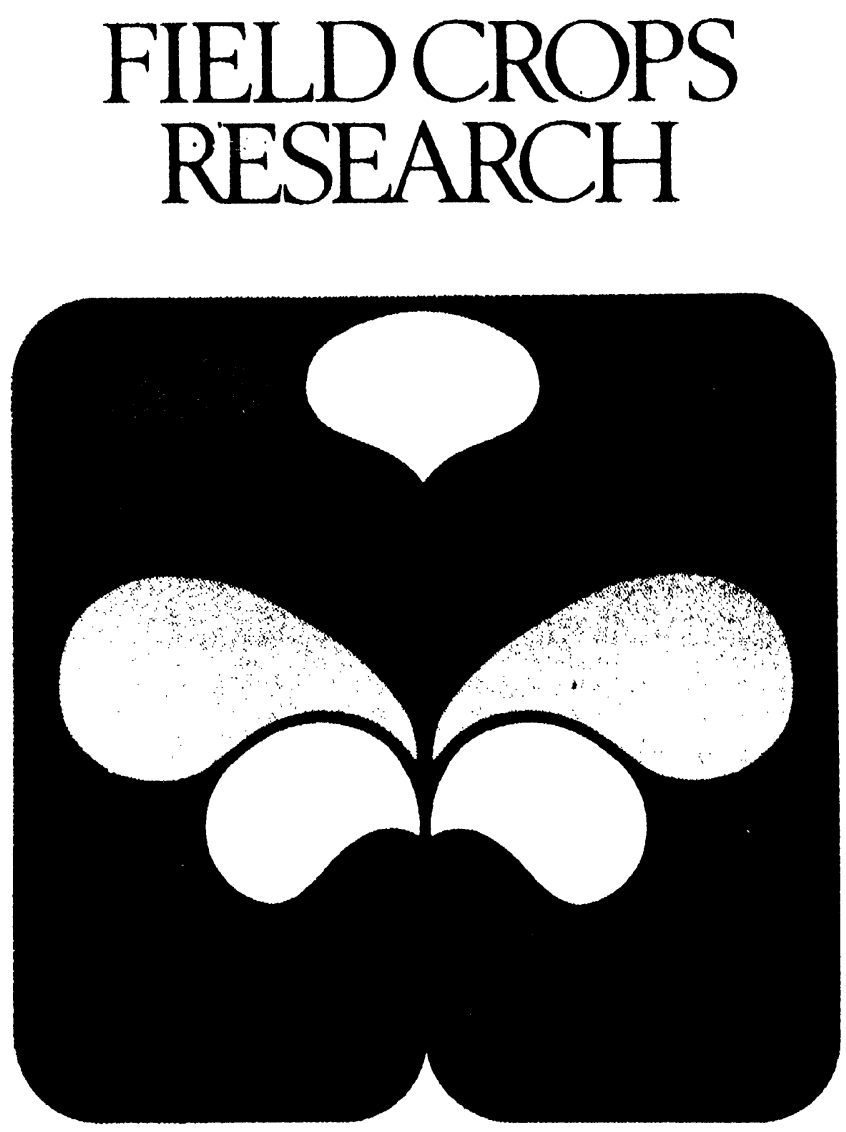

ELSEVIER 


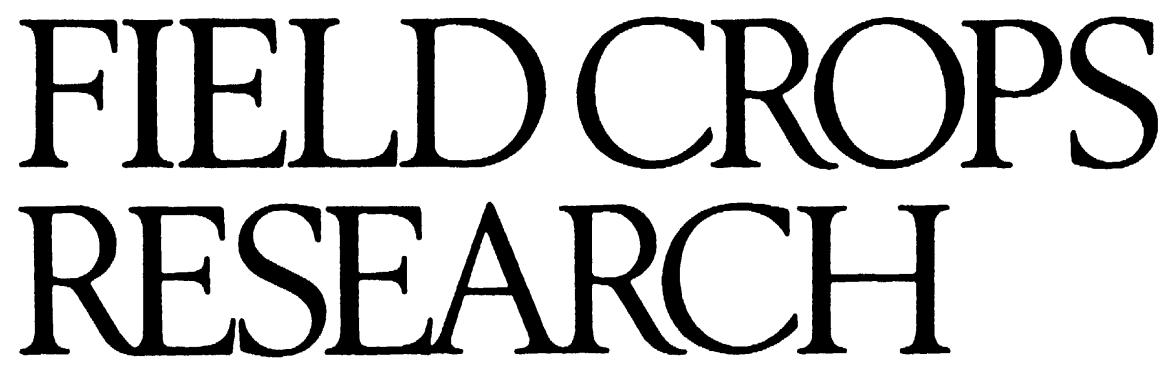

An International Journal

\section{Editors-in-Chief:}

For the Americas:

G.F. Arkin, Blackland Research Center, Texas Agricultural Experiment Station, P.O. Box 6112, TX 76503-6112, U.S.A.

For rest-of-the-world:

E. Lester, 19 Kirkwick Avenue, Harpenden, Herts. AL5 2QU, Great Britain

\section{Aims and scope.}

The journal publishes research results of international relevance arising from the scientific stud] of crops and farming systems. The subject fields covered include crop agronomy, improvement, physiology, ecology and protection; soil and water management; and farming systems. Crops dealt with are: cereals, non-cereal carbohydrate erops, pulses, sugar crops, oil crops, fibre crops, beverage crops, rubber, tobacco, and forages. Crop storage, transport and utilization, or social and economic aspects of crop production are outside the scope of the journal.

\section{Submission of articles.}

Manuscripts should be submitted in triplicate to the Editorial Secretariat, Field Crops Research, P.O. Box 330, 1000 AH Amsterdam, The Netherlands. Submissions from the Americas should be sent directly to Professor Arkin. 


\title{
Effect of Timing of Water Deficit on Pearl Millet (Pennisetum americanum $)^{1}$
}

\author{
V. MAHALAKSHMI, F.R. BIDINGER and D.S. RAJU \\ International Crops Research Institute for the Semi-Arid Tropics (ICRISAT), Patancheru \\ P.O., Andhra Pradesh 502324 (India)
}

'ICRISAT Journal article No 547.

(Accepted 24 July 1986)

\begin{abstract}
Mahalakshmi, V., Bidinger, F.R. and Raju, D.S., 1987. Effect of timing of water deficit on pearl millet (Pennisetum americanum). Field Crops Res., 15: 327-339.

The susceptibility of pearl millet to soil water deficits at different times of growth was determined in field experiments conducted over 2 years. Grain yields and yield components were expressed as ratios of stressed to non-stressed treatments. Where water deficit was imposed earlier in crop growth and then relieved, the time of termination of stress from flowering determined the extent of grain yield loss. Water stress relieved at anthesis or early grain filling had little adverse effect on the grain yield because additional tillers produced panicles. This response by tillers was less evident and grain yields were more severely reduced when water stress was not relieved until after flowering. When stress was imposed late in crop growth and not relieved, the time of initiation of stress was directly related to the extent of loss in grain yield. Thus susceptibility to midseason drought stress was related to the time stress was terminated and in late-season drought to the time stress was initiated.
\end{abstract}

\section{INTRODUCTION}

Pearl millet (Pennisetum americanum (L.) Leeke) is one of the most important cereals in the semi-arid regions of South Asia and sub-Saharan Africa. It is grown almost entirely as a rain-fed crop in areas where the interand intra-seasonal variation in rainfall is the single most important environmental factor limiting its productivity.

It is well documented that crops have varying sensitivities to water deficits at different growth stages, as measured by grain yield losses (Salter and Goode, 1967; Doorenbos and Kassam, 1979). Maximum sensitivity is usually at one of those stages where critical steps in the reproductive process occur (Slatyer, 1969 ). For determinate crops, these are usually the late floral development, flowering, and early grain-filling stages; for indeterminate crops timing of stress 
may be less critical as the reproductive phase extends over a longer period and provides more opportunity for compensation.

Prediction of the effects of stresses on grain yields (see Hiler and Howell, 1983) requires estimates of relative sensitivity of different stages of growth to periods of stress. Such data have been assembled for discrete growth stages for certain crops (references above) but are generally not available with the degree of detail necessary for such predictions. In pearl millet, for example, there are only reports to show that drought stress occurring early in crop growth has little effect on grain yields (Lahiri and Kharabanda, 1965) and that susceptibility to stress increases at and after flowering (Mahalakshmi and Bidinger, 1985b).

In rainfed crops, drought stress can occur at any time during crop growth, and crop susceptibility to drought stress is a continuously variable function rather than a discrete function; this point is often ignored. The data from this study were used to attempt to evaluate changing susceptibility of crop yield to timing of stress occurrence as a continuous function.

\section{MATERIAL AND METHODS}

The experiments were conducted in a medium-depth (ca. $1 \mathrm{~m}$ ) Alfisol, a member of clayey-skeletal, mixed isohyperthermic family of Udic Rhodustalfs, at the International Crops Research Institute for the Semi-Arid Tropics (ICRISAT), Patancheru, Andhra Pradesh, India, during the 1978 and 1979 dry seasons (January-May). This is a normally rain-free period with high maximum air temperatures $\left(35-40^{\circ} \mathrm{C}\right)$, low mid-day relative humidities (20-30\%) and high evaporation rates $\left(8-11 \mathrm{~mm}^{-1 a y}{ }^{-1}\right)$. The crop was irrigated to near field capacity by surface flooding for 2-3 h at approximately weekly intervals. Drought stress treatments were imposed by withholding irrigation during selected treatment periods. Soil water was not measured, but as the total available water-holding capacity of the soil was approximately 100 $\mathrm{mm}$, the crop was subjected to relatively severe water deficits in the drought stress treatments, which averaged 20 days duration.

All experiments were conducted as split plot designs with four replications. Time-of-stress (i.e., irrigation) treatments in the form of irrigation basins $(9 \times 9 \mathrm{~m})$ were randomized within replications as main plots. Genotypes were randomized within the main plots as sub-plots.

Pearl millet seeds were machine-sown in rows on level terraces, prior to placing the cross bunds which formed the individual irrigation treatment basins. The sub-plot unit consisted of four rows, $4.0 \mathrm{~m}$ long and $0.5 \mathrm{~m}$ apart. Rows were sown more thickly than the required plant density and thinned to $0.2 \mathrm{~m}$ between plants when the crop was 10 days old. Nitrogen and phosphate each were incorporated at the rate of $40 \mathrm{~kg} \mathrm{ha}^{-1}$ into soil prior to sowing and an additional $40 \mathrm{~kg} \mathrm{ha}^{-1} \mathrm{~N}$ was banded into rows 15 days after emergence. The 


\section{TABLE 1}

List and description of genotypes used in three experiments, based on the irrigated control treatment data

\begin{tabular}{|c|c|c|c|c|c|}
\hline Genotype & Genetic constitution & Origin & $\begin{array}{l}\text { Days to } \\
\text { flowering }\end{array}$ & $\begin{array}{l}\text { Panicles } \\
\left(\text { no. } / \mathrm{m}^{2}\right)\end{array}$ & $\begin{array}{l}\text { Gra } \\
\text { yiel }\end{array}$ \\
\hline \multicolumn{6}{|c|}{ Experiment I (1978) } \\
\hline BK 560 & $F_{1}$ Hybrid & India & 39 & 42 & 330 \\
\hline $1 / 2 \mathrm{HK}$ & Open-pollinated variety & Niger & 44 & 25 & 186 \\
\hline 700441 & Breeding line & Nigeria & 40 & 25 & 310 \\
\hline HB5 & $F_{1}$ hybrid & India & 40 & 41 & 229 \\
\hline Serere 17 & Breeding line & Uganda & 41 & 26 & 282 \\
\hline IP 2788 & Germplasm accession & Chad & 40 & 32 & 198 \\
\hline B 282 & Germplasm accession & Botswana & 50 & 27 & 222 \\
\hline Ex Bornu & Landrace variety & Nigeria & 47 & 18 & 234 \\
\hline
\end{tabular}

Experiment II (1978)

$\begin{array}{llllll}\text { BK 560 } & \text { F }_{1} \text { Hybrid } & \text { India } & 40 & 55 & 339 \\ \text { 1/2 HK } & \text { Open-pollinated variety } & \text { Niger } & 45 & 22 & 226 \\ 700441 & \text { Breeding line } & \text { Nigeria } & 42 & 26 & 250 \\ \text { HB 5 } & \text { F hybrid } & \text { India } & 41 & 48 & 223 \\ \text { Serere } 17 & \text { Breeding line } & \text { Uganda } & 44 & 31 & 284 \\ \text { IP } 2788 & \text { Germplasm accession } & \text { Chad } & 41 & 38 & 200\end{array}$

Experiment III (1979)

\begin{tabular}{llllll} 
BK 560 & F $_{1}$ Hybrid & India & 38 & 85 & 294 \\
PHB 14 & F Hybrid & India & 43 & 59 & 194 \\
700441 & Breeding line & Nigeria & 52 & 31 & 172 \\
Serere 17 & Breeding line & Uganda & 44 & 39 & 274 \\
BJ 104 & F $_{1}$ hybrid & India & 37 & 76 & 291 \\
B 282 & Germplasm accession & Botswana & 50 & 45 & 162 \\
Mali NKK & Open-pollinated variety & Mali & 44 & 44 & 224 \\
700256 & Breeding line & Nigeria & 46 & 37 & 201 \\
\hline
\end{tabular}

plots were kept weed-free and since this was a dry season, there was no incidence of any disease or pest.

Six to eight genotypes used in each experiment were selected to represent the geographic and phenotypic variability in pearl millet (Table 1). Some of the genotypes were common to all these experiments; however, as the objective of the experiments was to describe the response of the species rather than that 
of the individual genotypes, all analyses were performed on treatment means averaged over all genotypes.

Two types of stress treatments were used in these experiments: (1) midseason stress initiated at different times between floral initiation and early grain filling, with rewatering at the end of the treatment period; and (2) terminal stress initiated at or after flowering and no further rewatering. Each experiment also included a fully irrigated control. The specific treatments used in each of the three experiments are described in Table 2, along with cumulative United States Weather Bureau Class A pan evaporation, mean temperatures, and total rainfall received during each of the stress treatment periods.

The midseason treatments included different times of stress initiation (Experiments I and III) and different durations of stress initiated at the same time (Experiment II). These treatments essentially measured the effects of drought stress on the ability of the crop to recover following rewatering. The terminal stress treatments (Experiments I and III) which were initiated at different times after flowering measured the effects of stress on grain setting and grain filling (Table 2).

Days to flowering and height of the main shoot at maturity were recorded. The central two rows of $3 \mathrm{~m}\left(3 \mathrm{~m}^{2}\right)$ were harvested at maturity for determination of yield and yield components.

Individual experiments were first analysed as split plot designs; genotype $\times$ treatment effects were not significant for any of the variables measured. Hence only treatment means and standard errors are reported (Table 3 ). Since genotypes differed in potential yield, data for each genotype were expressed as a percentage of the non-stressed control and the percentages averaged over genotypes for estimating the effect of the timing of stress. Although there were differences between years and treatments in the total evaporative demand during each treatment, it was found that the data for the 2 years could be effectively combined on the basis of the time stress was terminated (midseason stress) or initiated (terminal stress) relative to flowering, rather than on the basis of specific growth stages.

This was useful as many of the stress treatments spanned more than one growth stage and because flowering is both the most easily determined phenological stage and a key one in terms of stress effects on various yield components.

\section{RESULTS AND DISCUSSION}

\section{Timing of midseason stress}

The midseason stress treatments in both Experiments I and III were intitiated at approximately 10-day intervals, beginning 18 days after emergence (DAE) in Experiment I and 25 DAE in Experiment III (Table 2). The dura- 
TABLE 2

Stress treatments - expressed as days from emergence (DAE) from the beginning to the end of the stress period - and weather variables during the same period

\begin{tabular}{|c|c|c|c|c|c|c|}
\hline \multirow{2}{*}{$\begin{array}{l}\text { Stress } \\
\text { treatment } \\
\text { (DAE) }\end{array}$} & \multirow[t]{2}{*}{ ' } & \multirow{2}{*}{$\begin{array}{l}\text { Key } \\
\text { timing }\end{array}$} & \multirow{2}{*}{$\begin{array}{l}\text { Class A pan } \\
\text { evaporation } \\
(\mathrm{mm})\end{array}$} & \multicolumn{2}{|c|}{ Average temperature $\left({ }^{\circ} \mathrm{C}\right)$} & \multirow{2}{*}{$\begin{array}{l}\text { Total } \\
\text { rainfal } \\
(\mathrm{mm})\end{array}$} \\
\hline & & & & maximum & minimum & \\
\hline
\end{tabular}

Experiment I (1978)

Midseason stress

$18-38$

$28-46$

$38-52$

46-58

$-5^{a}$

$+3^{\mathrm{a}}$

$+9^{\mathrm{a}}$

$+15^{\mathrm{a}}$

163

176

136

129

Terminal stress

$\begin{array}{ll}\text { 46-Mat } & +3^{\mathrm{b}} \\ 52-\text { Mat } & +9^{\mathrm{b}} \\ 58-\text { Mat } & +15^{\mathrm{b}}\end{array}$

58-Mat

$+15^{\mathrm{b}}$

Experiment II (1978)

Midseason stress

$\begin{array}{lll}18-38 & 20^{\mathrm{c}} & 163 \\ 18-46 & 28^{\mathrm{c}} & 238 \\ 18-52 & 34^{\mathrm{c}} & 299 \\ 18-60 & 40^{\mathrm{c}} & 368\end{array}$

Experiment III (1979)

\section{Midseason stress}

$25-48$
$25-57$
$35-57$
$48-68$

$\begin{array}{cc}+4^{\mathrm{a}}, 23^{\mathrm{c}} & 204 \\ 32^{\mathrm{c}} & 341 \\ +13^{\mathrm{a}} & 256 \\ +24^{\mathrm{a}} & 239\end{array}$

33.2

34.1

35.4

37.3

31.5

32.0

32.5

33.1

36.2

37.1

37.8

21.7

22.1

22.6

18.7

18.7

19.5

21.3

13

0

4

4

$\mathrm{mm}$ )

16.7

18.7

13

18.0

13

18.5

17

18.2

21.5

19.1

6

6

6

Terminal stress
35-Mat
$-9^{b}$
48-Mat
$+4^{b}$
58-Mat
$+14^{\mathrm{b}}$
a Termination of stress (days from flowering)
'Initiation of stress (days from flowering)
'Duration of stress (days)

33.0

19.1

37.5

21.9

35.0

22.1

Mat = maturity 


\section{TABLE 3}

Treatment means ( $n=32$ for Experiments I \& III and $n=24$ for Experiment II) for plant height, grain yield and yield components in the three experiments

\begin{tabular}{llllll}
\hline $\begin{array}{l}\text { Stress treatment } \\
\text { (DAE) }\end{array}$ & $\begin{array}{l}\text { Height } \\
(\mathrm{cm})\end{array}$ & $\begin{array}{l}\text { Grain yield } \\
\left(\mathrm{g} \mathrm{m}^{-2}\right)\end{array}$ & $\begin{array}{l}\text { No. of } \\
\text { panicles } \\
\mathrm{m}^{-2}\end{array}$ & $\begin{array}{l}\text { No. of grains } \\
\left(10^{2} / \text { panicle }\right)\end{array}$ & $\begin{array}{l}\text { Grain wt. (g } \\
\text { per 1000) }\end{array}$
\end{tabular}

Experiment I (1978)

Midseason stress

$\begin{array}{rrrrrr}18-38 & 110 & 212 & 30 & 11.2 & 7.0 \\ 28-46 & 98 & 199 & 33 & 9.2 & 6.8 \\ 38-52 & 97 & 180 & 36 & 7.2 & 6.8 \\ 46-58 & 113 & 131 & 32 & 6.6 & 6.6\end{array}$

Terminal stress

$\begin{array}{lrrrrr}\text { 46-Mat } & 128 & 80 & 19 & 8.7 & 5.3 \\ \text { 52-Mat } & 142 & 120 & 25 & 8.9 & 6.0 \\ \text { 58-Mat } & 134 & 176 & 25 & 11.5 & 6.6 \\ \text { Control } & 118 & 249 & 32 & 11.0 & 7.5 \\ \text { S.E. }^{1} & \pm 3.7 & \pm 17.8 & \pm 3.2 & \pm 0.75 & \pm 0.28\end{array}$

Experiment II (1978)

\begin{tabular}{|c|c|c|c|c|c|}
\hline \multicolumn{6}{|c|}{ Midseason stress } \\
\hline $18-38$ & 103 & 209 & 36 & 9.2 & 6.9 \\
\hline $18-46$ & 103 & 183 & 40 & 7.0 & 6.7 . \\
\hline $18-53$ & 98 & 134 & 36 & 6.5 & 6.0 \\
\hline $18-60$ & 91 & 68 & 26 & 5.0 & 5.3 \\
\hline Control & 115 & 254 & 37 & 10.8 & 7.3 \\
\hline S.E. & $\pm \quad 2.9$ & \pm 16.2 & \pm 3.5 & \pm 0.67 & \pm 0.19 \\
\hline \multicolumn{6}{|c|}{ Experiment III (1979) } \\
\hline \multicolumn{6}{|c|}{ Midseason stress } \\
\hline $25-48$ & 117 & 208 & 55 & 9.2 & 6.0 \\
\hline $25-57$ & 105 & 110 & 48 & 7.6 & 4.9 \\
\hline $35-57$ & 118 & 157 & 51 & 7.9 & 5.7 \\
\hline $48-68$ & 125 & 94 & 37 & 7.7 & 4.6 \\
\hline \multicolumn{6}{|c|}{ Terminal stress } \\
\hline 35-Mat & 99 & 55 & 20 & 7.9 & 4.3 \\
\hline 48-Mat & 129 & 76 & 32 & 6.8 & 4.2 \\
\hline 58-Mat & 146 & 125 & 34 & 8.4 & 5.3 \\
\hline Control & 140 & 226 & 52 & 10.7 & 6.1 \\
\hline S.E. & $\pm \quad 4.1$ & $\pm \quad 7.8$ & \pm 3.2 & \pm 0.63 & \pm 0.22 \\
\hline
\end{tabular}

${ }^{1}$ Standard error for comparing treatment means

Mat = Maturity 
tion was reduced in the later-initiated treatments (from 20 to 12 days in I and 23 to 20 days in III ), in an attempt to adjust for increasing evaporative demand in these treatments. Total pan evaporation during the treatment period for the various treatments indicated differences between years as well as some differences among treatments within each year (Table 2). Differences between years were mainly a result of small amounts of rain and consequently a lower evaporative demand during the first year (Table 2). The number of days to flowering was not affected by the treatments in either experiment, indicating that the stress was not so severe, even in the later treatments, as to delay development (data not presented).

Crop growth was affected by stress, resulting in reduced crop height, particularly when the stress was applied during the normal period of stem elongation (30-45 DAE) (Table 3). Grain yields were progressively reduced, with the maximum reduction occurring in the later-initiated (46-58 and 48-68 DAE) treatments in both experiments. The yield reductions in the earliest treatments (18-38 and 25-48 DAE) were not significant in either experiment, despite the fact that these crops were stressed during most of the panicle development period.

Stress affected the yield components differentially, depending on the time of occurrence. The final number of panicles was not significantly affected by any of the midseason treatments, with the exception of the 48-68 DAE treatment in Experiment III, in which stress was actually initiated after flowering in all cultivars ( Table 3 ). In contrast, the number of grains per panicle decreased progressively as stress initiation was delayed. Therefore, the number of grains per unit area primarily followed changes in number of grains per panicle. Individual grain mass was also progressively reduced with the delay in onset of stress, but the reduction in grain mass was significant only in the treatments where stress was not relieved until after flowering (Table 3 ).

Relative grain yield in the midseason stress was directly related to the time of stress termination (Fig. 1A). Yield reductions were small $(10 \%)$ if the stress was terminated prior to flowering, but were progressively more severe with the later time of stress termination. The relationship fitted well considering the treatments applied were not of identical intensity, either within or between years. Changes in relative grain yields with time of termination of stress were primarily a result of changes in relative number of grains per unit area although there was also a slight change in relative grain size (Fig. 1B and 1C).

Crop susceptibility indices for other cereals (Hiler et al., 1974; Doorenbos and Kassam, 1979) generally are at maximum during the periods immediately prior to, during, and immediately following flowering. Susceptibility clearly increases in pearl millet after flowering but this study and earlier work (Mahalakshmi and Bidinger, 1985b) indicate that the crop has a low sensitivity up to the time of flowering of the main shoot. Where midseason stress treatments in pearl millet are terminated at or before flowering, a significant increase in 


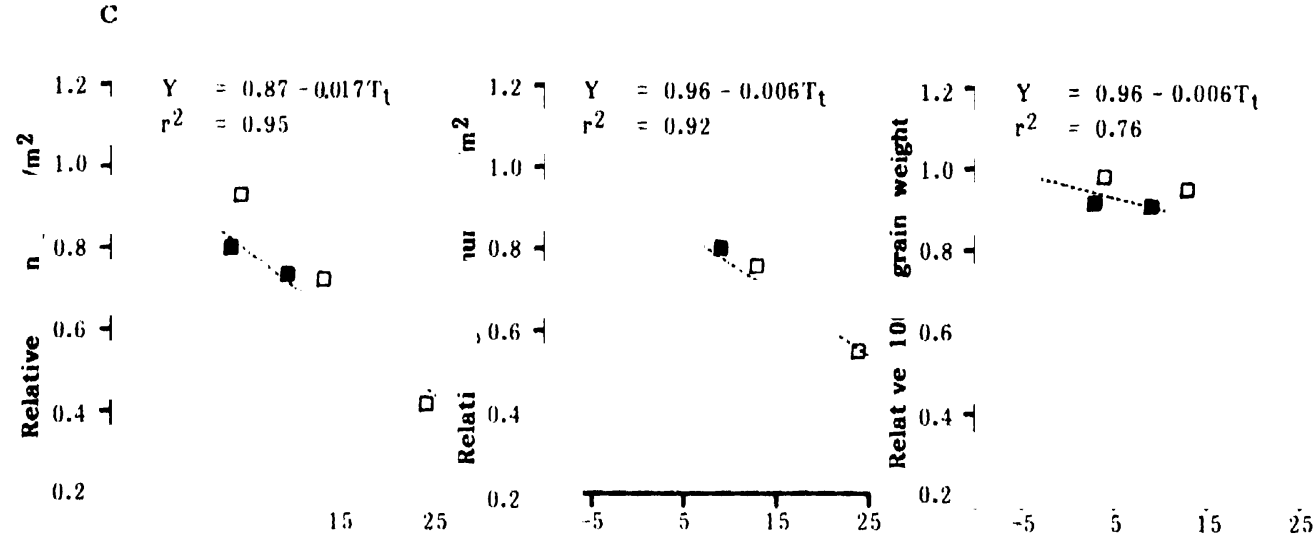

Stress termination (days from flowering)

Fig. 1. Relative (stress/control) grain yield $\left(R_{y}\right)$ and yield components in the midseason stress as a function of time of termination $\left(T_{t}\right)$ of the stress. Data are from Experiment $I(a)$ and Experiment III ( $\square$ ). Points represent means of 8 genotypes replicated 4 times $(n=32)$.

numbers of productive tillers occurs, which fully compensates for the losses in grain number and grain yield per individual panicle (Mahalakshmi and Bidinger, 1986). This tolerance to midseason stress seems to be related to the high degree of asynchrony of tiller development and delaying of flowering in pearl millet (Ramond, 1968; Lambert, 1983; Pearson and Coldrake, 1983). As the total panicle development stage (panicle initiation to flowering) is only 25-35 days in this crop, individual tiller development can be quite widely separated (by as much as 15 days) during this stage. In addition, a period of drought stress during the panicle development stage has been shown to delay the development of the later tillers; these resume development and growth only after the stress is terrninated and proceed to produce a normal yield or, in certain cases, continue their development where they would not have done so under non-stressed conditions (Mahalakshmi and Bidinger, 1985a).

These two responses, asynchronous tiller development and delaying of flowering, provide effective compensation for grain-yield losses in the earlier shoots, which develop and flower during the stress period. Cereals with more synchronous developmental patterns are more vulnerable to periods of stress during panicle development and flowering, as a much higher percentage of shoots are in a sensitive stage at the same time. (Lewis et al., 1974; Stewart et al., 1975; Fischer et al., 1977). In contrast, a species with a less-synchronized developmental pattern has the potential for the adjustments discussed above for pearl millet (Slatyer, 1969).

\section{Duration of midseason stress}

Treatments examining the effects of duration of midseason stress included all of Experiment II and the first two treatments (25-48 and 25-57 DAE) in 

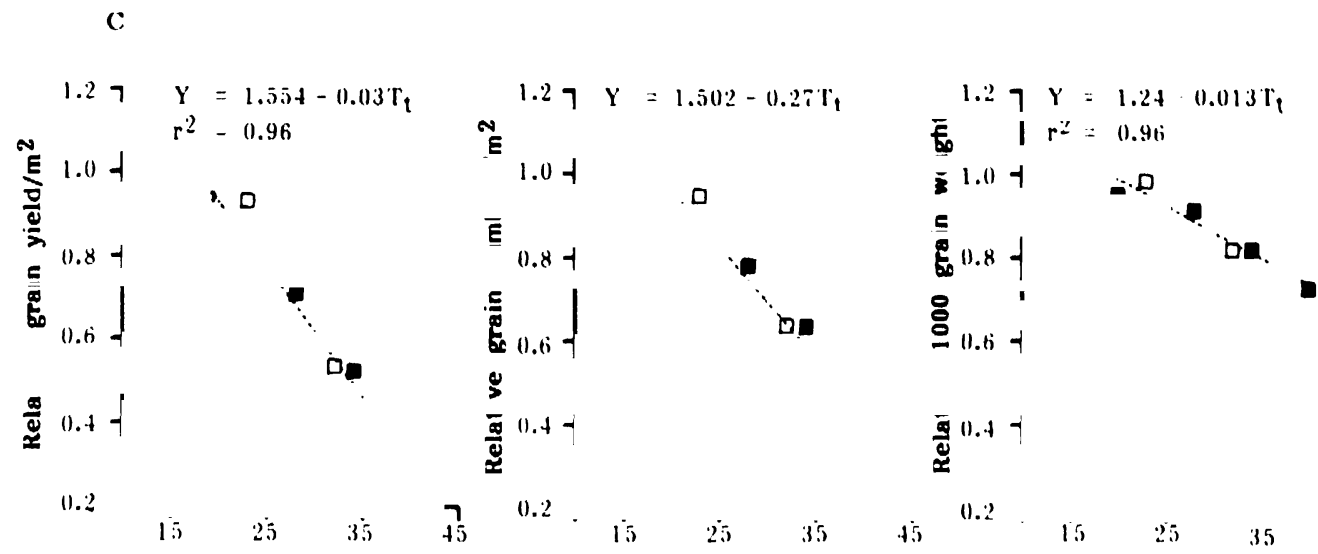

Stress duration (days)

Fig. 2. Relative (stress/control) grain yield $\left(R_{y}\right)$ and yield components in the midseason stress as a function of duration of stress. Data are from Experiment II ( $\square)$ and Experiment III ( $u)$. Points represent means of 6-8 genotypes replicated 4 times ( $n=24$ for Experiment II and $n=32$ for Experiment III).

Experiment III. Cumulative pan evaporation was again higher for comparable treatments in Experiment III, but in both experiments pan evaporation increased regularly with increasing duration of the stress period (Table 2).

As in the timing-of-stress experiments, stress was not severe enough to affect the time to flowering, but reduced crop height significantly as the stress duration increased (Table 3 ). Losses of grain yield in the shortest period of stress in both experiments (18-38 and 25-48 DAE) were not significant, but increased and became significant as the length of the stress period increased (Table 3 ).

As with the timing-of-midseason-stress treatments, yield components were affected differentially by the stress duration treatments. Number of panicles per unit area was affected only by the longest stress treatment (Experiment II). However, the number of grains per panicle, and therefore per unit area, was progressively reduced as the duration of stress increased (Table 3). Individual grain size was similarly affected, as a greater proportion of the normal grain-filling period was subjected to stress in the longer-duration treatments, at least in tillers that flowered during the stress period.

Relative grain yields during midseason stress declined approximately linearly with increasing duration of the stress period (Fig. $2 \mathrm{C}$ ). This was primarily because of the change in relative number of grains per unit area which declined at twice the rate of relative grain size (Figs. $2 \mathrm{~B}$ and $3 \mathrm{C}$ ).

Effects of stress duration are hard to interpret in the midseason treatments, because duration and time of stress termination are confounded. The effects of increasing duration of stress resemble very closely the effects of delaying the timing of termination of stress (compare Figs. 1 and 2). Much of the pre- 

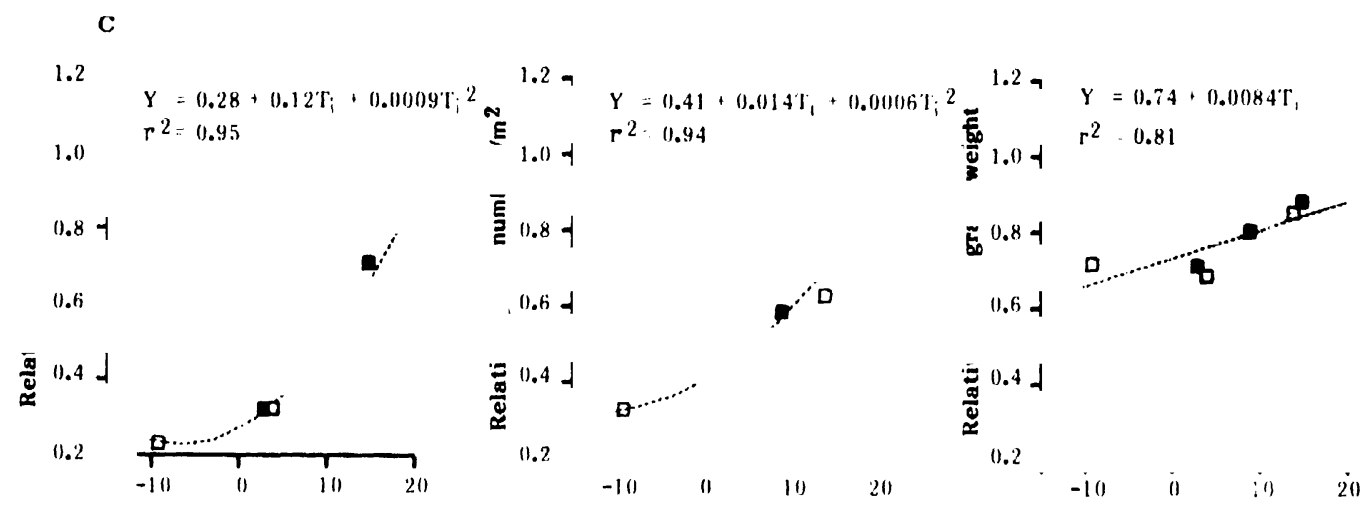

Stress initiation (days from flowering)

Fig. 3. Relative (stress/control) grain yield $\left(R_{y}\right)$ and yield components in the terminal stress as a function of time of stress initiation $\left(T_{i}\right)$. Data are from Experiment $I(\boldsymbol{d})$ and Experiment III ( $\mathrm{c})$. Points represent means of 8 genotypes replicated 4 times $(n=32)$.

vious discussion on the effects from time of stress termination appears applicable also to the duration treatments.

In an attempt to test the relative effects of time and duration of stress on yields, the 1978 data (where there were equal numbers of treatments of both types) were used to regress relative yields against both timing and duration. Regression coefficients indicated a larger effect for a delay of one day in termination of stress ( $1.8 \%$ loss in relative yield) than for an extension of one day of the stress $(0.6 \%$ loss in relative yield). Therefore, the effects indicated in Fig. 2 are clearly confounded ones, with the time of termination as the major factor. In fact, a simple linear regression of yield on time of stress termination for the same combined data set accounted for $81 \%$ of the variation in yield, compared to $90 \%$ for the multiple regression using both timing and duration. Midseason stress in pearl millet, therefore, should be considered primarily in terms of timing rather than of duration.

\section{Timing/duration of terminal stress}

The terminal stress treatments were imposed after flowering in Experiment I, and approximately one week before flowering in Experiment III (Table 2). Through an oversight, physiological maturity was not recorded in these treatments; so comparison of treatments in terms of total potential evaporation is not possible. In all cases total available water was similar at the times the treatments were initiated and, therefore, the total evaporation deficit in each case was inversely related to the time stress was initiated.

In each year, crop height was reduced by the earliest terminal stress treatment, where stress was imposed prior to flowering - in the later cultivars in Experiment I and all cultivars in Experiment III. Grain yields were very severely 
reduced by all terminal stress treatments with the severity inversely related to the time stress was initiated (Table 3 ).

Effects of terminal stress on yield components differed from the effects of midseason stress, but not always in the pattern expected. Number of panicles per unit area was significantly reduced in treatments initiated earlier than 7 days after flowering ( $46 \mathrm{DAE}$ to maturity in Experiment I, and 35 and $48 \mathrm{DAE}$ to maturity in Experiment III) and in the treatment initiated 14 days after flowering in Experiment III (58 DAE to maturity), where stress was more severe (Table 3 ). Number of grains per panicle was reduced in all terminal stress treatments except the latest-initiated one in Experiment III, although there was not clear patterns in the effect of time of initiation of stress (Table 3 ). The number of grains per panicle is a mean of the main shoot panicle plus the varying number of tiller panicles in the different treatments. Tillers eliminated by the stress, particularly by the earlier terminal stress treatments, were the late and less-productive ones. Their loss may have had a positive effect on the mean number of grains per panicle (calculated from the remaining panicles), which may have partially offset the reduction in number of grains per panicle from direct effect of stress on pollination and fertilizitation. Individual grain size, in contrast, was reduced linearly the earlier the onset of stress (Table $3)$.

Relative yields in the terminal stress treatment were closely related to the time of stress initiation (Fig. 3A). Yield reductions were very severe (70-80\%) when the stress was initated prior to flowering, but the effect declined rapidly as the onset of stress was delayed. Similar curvilinear responses have been reported for spring wheat when timing was varied for initiation of terminal stress (Fischer and Maurer, 1978). Relative yield reductions were primarily from effects of time of stress initiation on relative number of grains per unit area, although relative grain size was generally smaller in all treatments (Figs. $3 \mathrm{~B}$ and $3 \mathrm{C}$ ). This type of stress, which occurs when rains end early in tropical climates with marked seasonal rainfall patterns, is not an uncommon occurrence. Clearly, a premature end of the rains has very substantial effects on grain yields under the characteristically high evaporative conditions in these environments.

The asynchronous tillering habit in pearl millet, which was effective in reducing sensitivity to midseason stress, is a disadvantage rather than an advantage during terminal stress. The more the spread in development among tillers, the greater the percentage of tillers which enter the stress at developmental stages where they will be either eliminated entirely or subject to very severe reductions in grain set and grain fill. The elimination of a certain number of tillers is probably beneficial where no additional water will be available to the crop. However, tillers which reach flowering but produce little or no grain use a share of the water available, but contribute nothing to grain yield. Yield reductions in post-anthesis stress in more synchronously tillering cereals 
occur primarily through reductions in grain number per ear and grain mass rather than through reduction in ear number (Day et al., 1978; Hochman, 1982 ). However, terminal stress initiated before flowering in these cereals does affect ear numbers as well (Day et al., 1978).

The large changes in relative grain yields, for changes of about 10-20 days in the onset of the stress, emphasize the importance of fitting crop duration to the expected duration of available moisture for pearl millet. With no opportunity for adjustment in the case of terminal stress and with a special vulnerability in the form of later-maturing tillers, mean flowering dates must occur well within the period of available moisture to ensure an escape from terminal stress. Earlier flowering, however, may well increase crop vulnerability to a period of midseason stress if it means that this stress occurs after, rather than before, flowering.

\section{REFERENCES}

Day, W., Legg, B.G., French, B.K., Johnston, A.E., Lawlor, D.W. and Jeffers, W., 1978. A drought experiment using mobile shelters: the effect of drought on barley yield, water use and nutrient uptake. J. Agric. Sci., 91: 559-623.

Doorenbos, J. and Kassam, A.H., 1979. Yield response to water. Irrig. Drain. Pap. 33. FAO, Rome, $193 \mathrm{pp}$.

Fischer, R.A., Lindt, J.H. and Glave, A., 1977. Irrigation of dwarf wheats in the Yaqui valley of Mexico. Exp. Agric., 13: 353-368.

Fischer, R.A. and Maurer, R., 1978. Drought resistance in spring wheat cultivars. I. Grain yield responses. Aust. J. Agric. Res., 29: 897-912.

Hiler, E.A. and Howell, T.A., 1983. Irrigation options to avoid critical stress. In: H.M. Taylor, W.R. Jordan and T.R. Sinclair (Editors), Limitations to Efficient Water Use in Crop Production. American Society of Agronomy, Madison, WI, pp. 479-497.

Hiler, E.A., Howell, T.A., Lewis, R.B. and Boos, R.P., 1974. Irrigation timing by the stress day index method. Trans. ASAE, 17: 393-398.

Hochman, Z., 1982. Effect of water stress with phasic development on yield of wheat grown in semi-arid environment. Field Crops Res., 5: 55-67.

Lahiri, A.N. and Kharabanda, B.C., 1965. Studies of plant-water relationships: effects of moisture deficit at various developmental stages of bulrush millet. Proc. Natl. Inst. Sci. India, 31: 14-24.

Lambert, C., 1983. Effect of earliness on pearl millet (Pennisetum typhoides Stapf and Hubbard) development under natural conditions. Agron. Trop. 38: 4-15.

Lewis, R.B., Hiler, E.A. and Jordan, W.R., 1974. Susceptibility of grain sorghum to water deficit at three growth stages. Agron. J., 66: 589-591.

Mahalakshmi, V. and Bidinger, F.R., 1985a. Flowering response of pearl millet to water stress during panicle development. Ann. Appl. Biol., 106: 571-578.

Mahalakshmi, V. and Bidinger, F.R., 1985b. Water stress and time to floral initiation in pearl millet. J. Agric. Sci., 105: 437-44j.

Mahalakshmi, V. and Bidinger, F.R., 1986. Water deficit during panicle development in pearl millet: yield compensation by tillers. J. Agric. Sci., 106: 113-119.

Pearson, C.J. and Coldrake, P.D., 1983. Pennisetum americanum as a grain crop in Eastern Australia. Field Crops Res. 7: 265-282.

Raymond, D.C., 1968. For a better understanding of the crop growth and development of pennisetum millets. Agron. Trop. 28: 844-863. 
Salter, P.J. and Goode, J.E., 1967. Crop Response to Water at Different Stages of Growth. Commonwealth Agricultural Bureaux, England, 246 pp.

Slatyer, R.O., 1969. Physiological significance of internal water relations to crop yield. In: J.D. Eastin, F.A. Haskins, C.Y. Sullivan and C.H.M. Van Bavel (Editors), Physiological Aspects of Crop Yield. American Society of Agronomy, Madison, WI, pp. 53-88.

Stewart, J.I., Misra, R.D., Pruitt, W.O. and Hagan, R.M., 1975. Irrigating corn and grain sorghum with deficient water supply. Trans. ASAE, 18: 270-280. 


\section{NOTE TO CONTRIBUTORS}

A detailed Guide for Authors is available upon request and is also printed in the first volume to appear each year. You are kindly asked to consult this guide. Please pay special attention to the following notes:

\section{Types of papers published in the journal}

- papers reporting results of original research - review articles - short communications - editorials

- book reviews - news and announcements.

\section{Language}

The official language of the journal is English.

\section{Preparation of the text}

(a) The manuscript should include at the beginning an abstract of not more than 400 words.

J) It should be typewritten with double spacing and wide margins. Words to be printed in italics should be underlined. SI units should be used throughout.

(c) The title page should include: the title, the name(s) of the author(s), and their affiliation(s).

(d) Submit original plus 2 copies of manuscript (original illustrations or computer printouts plus 2 photocopies - for photographs, 3 prints should be supplied).

\section{References}

(a) References in the text should be cited as the name of the author(s), followed by the year of publication.

(b) The reference list should be in alphabetical order and on sheets separate from the text.

\section{Tables}

Tables should be compiled on separate sheets. A title should be provided for each table and all tables should be referred to in the text.

\section{IIlustrations}

(a) Illustrations should be numbered consecutively and referred to in the text. All illustrations (line drawings, computer printouts and photographs) should be submitted separately, unmounted and not folded.

(b) Drawings should be fully annotated, the size of the lettering being appropriate to that of the drawings, but taking into account the possible need for reduction in size (preferably not more than $50 \%$ ). The page format of the journal should be considered when designing drawings.

c) Photographs must be of good quality, printed on glossy paper.

(d) Figure captions should be supplied on a separate sheet.

\section{Reprints and page charges}

There is no page charge. Fifty reprints of each article published will be supplied free of charge.

Additional reprints can be ordered on a reprint order form which is included with the proofs.

All contributions will be carefully refereed for international relevance and quality.

Submission of an article is understood to imply that the article is original and unpublished and is not being considered for publication elsewhere. 


\section{ALSO FROM ELSEVIER}

AGRICULTURAL ECONOMICS

AGRICULTURAL WATER MANAGEMENT

ANIMAL FEED SCIENCE AND TECHNOLOGY

ANIMAL REPRODUCTION SCIENCE

APPLIED ANIMAL BEHAVIOUR SCIENCE

AQUACULTURE

AQUATIC BOTANY

COMPUTERS AND ELECTRONICS IN AGRICULTURE

ECOLOGICAL MODELLING

ENERGY IN AGRICULTURE

EXPERIMEN'TAL AND APPLIED ACAROLOGY

FISHERIES RESEARCH

FOREST ECOLOGY AND MANAGEMENT

LANDSCAPE AND URBAN PLANNING

LIVESTOCK PRODUCTION SCIENCE

PREVENTIVE VETERINARY MEDICINE

RECLAMATION \& REVEGETATION RESEARCH

SCIENTIA HORTICULTURAE

SOIL \& TILLAGE RESEARCH

VETERINARY IMMUNOLOGY AND IMMUNOPATHOLOGY

VETERINARY MICROBIOLOGY

VETERINARY PARASITOLOGY

VETERINARY RESEARCH COMMUNICATIONS

- FULL DETAILS AND A FREE SAMPLE COPY AVAILABLE ON REQUEST

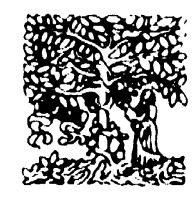

\section{ELSEVIER SCIENCE PUBLISHERS}

P.O. Box 330, 1000 AH Amsterdam, The Netherlands 